\title{
Assemblage structure: an overlooked component of human-mediated species movements among freshwater ecosystems
}

\author{
D. Andrew R. DRAKE, ${ }^{1}$ Farrah T. CHAN, ${ }^{2}$ Elizabeta BRISKI, ${ }^{1}$ Sarah A. BAILEY, ${ }^{1}$ Hugh J. MACISAAC ${ }^{2 *}$ \\ ${ }^{1}$ Great Lakes Laboratory for Fisheries and Aquatic Sciences, Fisheries and Oceans Canada, Burlington, Ontario, L7R 4A6, Canada; \\ ${ }^{2}$ Great Lakes Institute for Environmental Research, University of Windsor, Ontario, N9B 3P4, Canada \\ *Corresponding author: hughm@uwindsor.ca
}

\begin{abstract}
The spread and impact of alien species among freshwater ecosystems has increased with global trade and human movement; therefore, quantifying the role of anthropogenic and ecological factors that increase the risk of invasion is an important conservation goal. Two factors considered as null models when assessing the potential for invasion are colonization pressure (i.e., the number of species introduced) and propagule pressure [i.e., the number (propagule size), and frequency (propagule number), of individuals of each species introduced]. We translate the terminology of species abundance distributions to the invasion terminology of propagule size and colonization size (PS and CS, respectively). We conduct hypothesis testing to determine the underlying statistical species abundance distribution for zooplankton assemblages transported between freshwater ecosystems; and, on the basis of a lognormal distribution, construct four hypothetical assemblages spanning assemblage structure, rank-abundance gradient (e.g., even vs uneven), total abundance (of all species combined), and relative contribution of PS vs CS. For a given CS, many combinations of PS and total abundance can occur when transported assemblages conform to a lognormal species abundance distribution; therefore, for a given transportation event, many combinations of CS and PS are possible with potentially different ecological outcomes. An assemblage exhibiting high PS but low CS (species poor, but highly abundant) may overcome demographic barriers to establishment, but with lower certainty of amenable environmental conditions in the recipient region; whereas, the opposite extreme, high CS and low PS (species rich, but low abundance per species) may provide multiple opportunities for one of $\mathrm{n}$ arriving species to circumvent environmental barriers, albeit with lower potential to overcome demographic constraints. Species abundance distributions and the corresponding influence of CS and PS are some of many influential factors (e.g., demographic and genetic stochasticity, environmental variability, composition of recipient ecosystems) that will help refine an understanding of establishment risk following the human-mediated movement of species.
\end{abstract}

Key words: biological invasion, species abundance distribution, rank-abundance, colonization pressure, propagule pressure, risk assessment.

Received: May 2013. Accepted: October 2013.

\section{INTRODUCTION}

Aquatic ecosystems globally have been altered by the introduction and establishment of alien species. Species have been transported by numerous intentional and unintentional vectors (i.e., transport mechanisms) including aquaculture, species stocking, and ships' ballast water and hull fouling (Hulme et al., 2008; MacIsaac, 2011; Briski et al., 2013). Some alien species that establish in their recipient environment have strong ecological and economic impacts, drawing the attention of ecologists, economists, and management agencies (Leung et al., 2002; Lockwood et al., 2007; Hulme et al., 2008). The global community formally recognized the severity of biological invasions in the Convention on Biological Diversity in 1993 (CBD, 1993), which focused on the need to prevent the introduction and spread of alien invasive species. Given limited managerial resources and the probabilistic nature of invasions, much research has been devoted to the development of risk assessment protocols, which take either of two broad ap- proaches: screening individual species of concern (e.g., those that may be imported or inadvertently introduced) based on their life history attributes, global biogeography, and invasion history (Pheloung et al., 1999; Herborg et al., 2007b), or screening based upon vector characteristics (e.g., number and extent of propagules transported) and the environmental similarity of source and recipient ecosystems (Herborg et al., 2007a; Bradie et al., 2013; Chan et al., 2013; Seebens et al., 2013). Both approaches can be used to direct management, such as creation of species-specific white (allowed) and black (banned) trade lists, or by prioritizing regulatory actions at high-risk vectors. Vector approaches are particularly appealing because effective management of a vector may prevent introduction of numerous recognized and unrecognized alien species, whereas the former is, by its very nature, limited to individual species (Carlton and Ruiz, 2005).

Numerous alien species have established in freshwater ecosystems owing to a combination of deliberate stocking programs, unauthorized or unintentional introductions, 
range extensions, and natural dispersal (see MacIsaac, 2011). Many of these freshwater introductions involve fishes, reptiles, birds, mammals, invertebrates, or macrophytes, although most taxonomic groups have been, and will continue to be, introduced due to anthropogenic activity. The Laurentian Great lakes, Lakes Ladoga and Onega (Russia), and the Caspian Sea are unusual among freshwaters in that their canal connections to the sea allow ship associated vectors - namely ballast water release and hull fouling - to exchange species among freshwater habitats, circumventing the biogeographic barrier of salinity. Consequently, these freshwater ecosystems have notable invasion histories (Dumont et al., 2004; Ricciardi, 2006; Kurashov et al., 2012). Coastal marine ecosystems in the vicinity of ports have likewise been inundated by species associated with ballast water release, hull fouling, and other vectors (Ruiz et al., 2000, 2013; Occhipinti-Ambrogi et al., 2011; Edelist et al., 2012). Considering the numerous alien species in many freshwater ecosystems and polyvectic nature of introductions (Carlton and Ruiz, 2005), developing further insight into the role of vectors and characteristics of transported species may inform risk assessments and, in-turn, refine prevention strategies.

When quantifying species transported by vectors, invasion ecologists have often focused on the total abundance of propagules or the total number of species transported (Conn et al., 2010; Haska et al., 2012; Briski et al., 2013). Numerous experimental and theoretical studies have revealed a relationship between propagule pressure and the probability of establishment (Lockwood et al., 2005; Von Holle and Simberloff, 2005; Colautti et al., 2006; Simberloff, 2009; Gertzen et al., 2011); therefore, propagule pressure provides a suitable null model for invasions (Colautti et al., 2006; Lockwood et al., 2009). Large propagule pressure mitigates the properties of small population sizes such as low genetic variation, vulnerability to Allee effects, and environmental stochasticity (see Carlton et al., 2011). Nonetheless, for establishment to occur, overarching environmental conditions must be suitable for colonizing organisms; therefore, the relationship between propagule pressure and establishment is broadly context-dependent based on the similarity of source and recipient regions. Due to their physical characteristics, some species vectors, such as ships' ballast water and hull fouling (Lockwood et al., 2007; Hulme et al., 2008; Briski et al., 2013) have the potential to transport species assemblages (i.e., multiple species within a single human-mediated movement), in which each species will exhibit its own propagule size. The number of species transported and introduced (colonization pressure) has also been proposed as a null model for establishment (Lockwood et al., 2009); therefore, quantifying propagule and colonization pressures are important objectives for invasion ecology.

Here, we propose that many permutations of propagule and colonization sizes (PS and CS, respectively), rep- resenting the absolute number of propagules-per-species, and species, introduced during a single release event, are possible in relation to vector characteristics and the nature of the source community. Some vectors, particularly fish or invertebrate stocking of lakes, may involve the release of many individuals of a single species (high PS, low CS); whereas, other vectors like ballast water may involve release of many species of varying abundance (low to high PS, high CS). Estimating overall invasion risk is far more difficult in the latter case due the greater number of influential environmental and demographic characteristics (Wonham et al., 2013). Therefore, determining the structure of transported assemblages (e.g., elements of PS and $\mathrm{CS}$ as relative abundance among $n$ transported species) is a necessary step to evaluate the potential for establishment when alien assemblages are introduced.

Ecologists have long been interested in the structure of biological communities, such as the relative abundance of species within a given plot, island, or ecoregion (Preston, 1948; Whittaker, 1965). It is generally regarded that the assemblage of species within a given area will follow a lognormal distribution, with the number of species on the $y$-axis and the abundance of individuals on the $x$-axis. However, multiple distributions (e.g., geometric, logarithmic) are found in response to environmental disturbance or other factors (Ugland and Gray, 1982). The extent to which the lognormal distribution extends to species assemblages transported by vectors is unknown (Lockwood et al., 2009) and represents a key uncertainty in the transport and introduction of species among freshwater ecosystems. Certain propagule uptake mechanisms within vectors may give rise to transported assemblages that deviate in structure and composition from their source communities. Assessing the underlying species abundance distribution of transported assemblages is important to understand patterns of abundance across species number, which is a critical step to inform the potential for establishment among $n$ transported species.

Here, we translate the terminology of species abundance distributions and standard species rank-abundance plots to illustrate two key terms in invasion ecology: propagule size (PS; the position of a given transported species on the $y$-axis of the rank-abundance plot), and colonization size (CS; the count of ranked species along the $y$-axis; Fig. 1). Rank-abundance distributions allow the relative differences of PS across CS (i.e., the rank-abundance gradient) to be determined as a measure of the evenness of the transported assemblage (see Foster and Dunstan 2010 for a review of rank-abundance in ecology). Differences in the rank-abundance gradient will have potentially strong consequences for invasion ecology. For example, for a given CS, two alien assemblages transported by a vector may exhibit different total abundance of propagules and, therefore, different propagule sizes for 
each species (Fig. 2 A,B, $i v s i i$ ); they may also exhibit varying degrees of evenness, indicating similarity (even rank-abundance gradients; Fig. 2A) or dissimilarity (uneven rank-abundance gradients; Fig. 2B) of the propagule sizes between species. Further, strong differences in assemblage structure, demonstrated by opposing rank-abundance gradients and relative contributions of CS and PS, can exist for two assemblages of similar total abundance (Fig. 2C), indicating that, for a given transported assemblage of $n$ total propagules, many permutations of CS and PS are possible. Evidence from ballast water sampling of vessels arriving among Canadian ports indicates that the rank-abundance gradient of transported ballast assemblages varies widely, with some exhibiting extreme dominance by a few species and others exhibiting relatively even rank-abundance gradients (Fig. 3; assemblage data from Briski et al., 2012). Traditionally, a single species exhibiting high PS (e.g., the highest ranking species in assemblage $i$, Fig. 2C) has generated management concern given the presumed high probability of establishment. However, we propose that species-rich assemblages with low PS throughout may nevertheless exhibit a similar overall risk for the establishment of a single species (assemblage $i$, Fig. 2C), because the increased number of species provides heightened opportunity for at least one of the transported species to overcome the environmental barriers to establishment within the recipient ecosystem.

We have three primary objectives. First, to highlight one of the many standard ecological tools available for

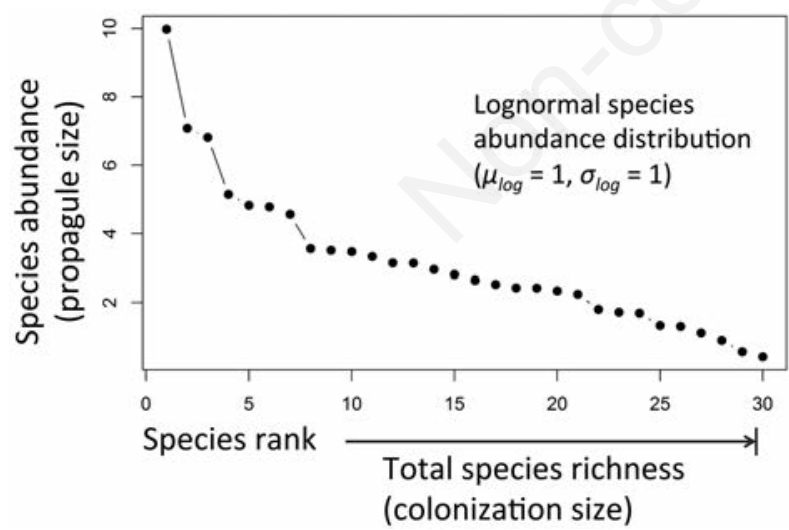

Fig. 1. Elements of a species rank-abundance distribution for quantifying human-mediated transport of alien assemblages. Colonization size (species number) is represented on the $x$-axis, while propagule size (number of individuals per species) is represented on the $y$-axis. The underlying species abundance distribution of the rank-abundance plot is lognormal $\left(\mu_{\log }=1\right.$, $\sigma_{\log }=1$ ), although many statistical distributions are possible in relation to environmental disturbance and other ecological factors. Shown is an assemblage of 30 species randomly selected from the predetermined lognormal parameters. invasion biologists, we translate the terminology of species rank-abundance distributions into the invasion terminology of propagule size and colonization size for assemblages of alien species transported by vectors. Second, we test the hypothesis that the species abundance distributions of assemblages transported by vectors follow a lognormal distribution; and, third, on the basis of hypothesis testing, we construct hypothetical examples of transported assemblages exhibiting opposing combinations of PS and CS. These assemblages allow us to highlight conceptual differences among various lognormal assemblages and rank-abundance gradients as they relate to differences in PS and CS; and, we illustrate that beyond simple summary measures of PS and CS, the species abundance distribution of arriving propagules can provide insight towards the potential for alien species establishment. We focus our discussion to transported assemblages contained in ballast water because it is the best characterized mass vector of alien species, because of current global management concern regarding ballast water, and because of the modelling opportunities provided by ballast water assemblages that span a wide range of CS and PS (Fig. 3).

\section{METHODS}

To determine the extent to which transported assemblages correspond to a lognormal species abundance distribution, we compiled data describing 28 freshwater zooplankton assemblages (details of sampling and species identities provided in Briski et al. 2012). For each assemblage, species richness and the total abundance of individuals for each species were recorded (see Fig. 3 for rank-abundance distributions of each assemblage; due to the physical limitations of ballast water sampling, assemblage data represent a standardized sample, propagules per cubic meter, of total organisms transported by a given ship). For each assemblage, we conducted a KolmogorovSmirnov goodness-of-fit test $(\alpha=0.05)$ to determine the degree of correspondence between the empirical data and a lognormal species abundance distribution. We then used maximum likelihood to determine the most probable lognormal parameters for each assemblage (i.e., $\mu_{\log }$, the mean parameter of the lognormal distribution, and $\sigma_{\mathrm{log}}$, the standard deviation parameter). For each transported assemblage, $\mu_{\log }, \sigma_{\log }$, CS, mean PS, total abundance of propagules, and the Kolmogorov-Smirnov $D$-statistic and $p$-values were recorded.

Following hypothesis testing, we constructed four distinct hypothetical assemblages transported by a vector (hereafter, assemblages $A, B, C$, and $D$ ) and conforming to a lognormal species abundance model but with intentionally different assemblage structure and combinations of CS and PS. To construct these hypothetical but realistic assemblages, we randomly sampled from lognormal distributions (1000 iterations for each assemblage, $A: 10$ 

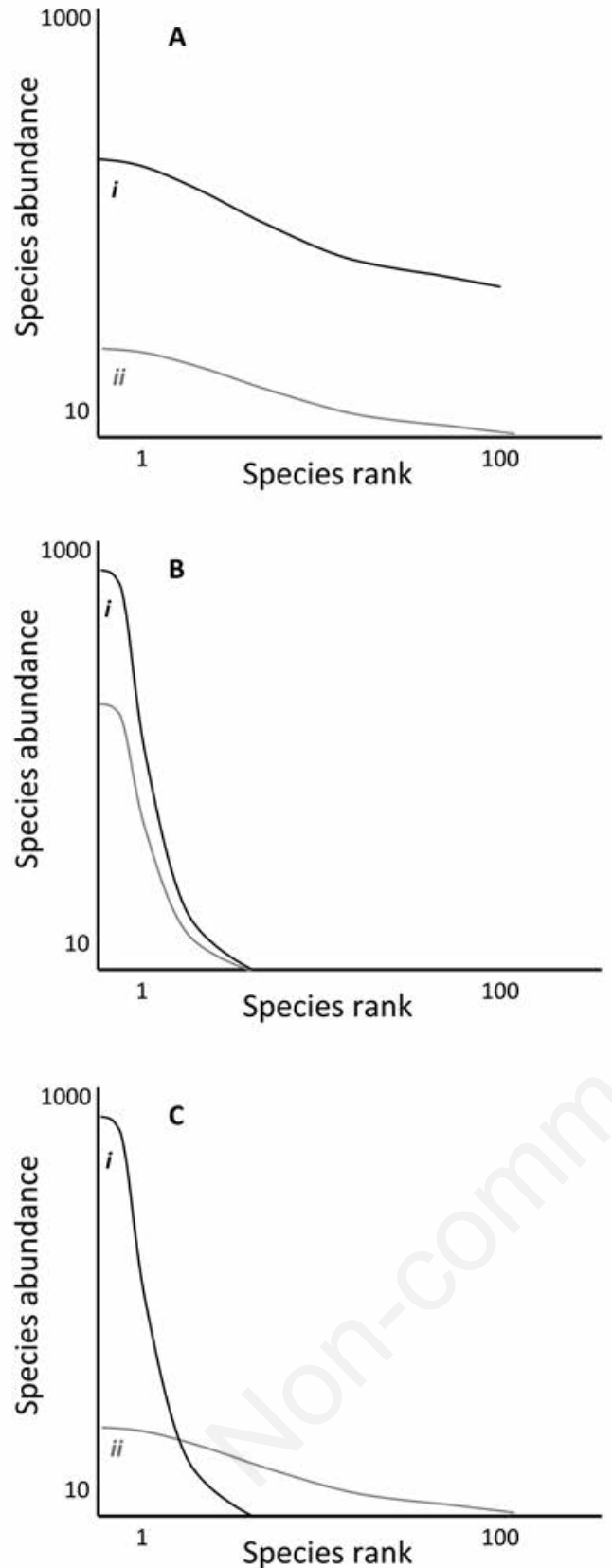

Fig. 2. Conceptual framework comparing species assemblages on the basis of propagule size ( $y$-axis) and colonization size ( $x$-axis). In panel $\mathrm{A}$, assemblages $i$ and $i i$ have identical colonization size $(\mathrm{CS} \approx 100)$. Both assemblages exhibit shallow rank-abundance gradients; $i$ total abundance $>i i$ total abundance. In panel B, $i$ and $i i$ have identical colonization pressure $(\mathrm{CS} \approx 30)$. Both assemblages have steep gradients; as with A, $i$ total abundance $>i i$ total abundance. In panels A and B, rank-abundance gradients are relatively similar between assemblages, but their PS and total abundance vary strongly. In panel $\mathrm{C}$, two hypothetical assemblages ( $i$ and $i$; $\approx 1000$ organisms each) represent compositional extremes of rankabundance gradients and contribution of PS and CS for a given assemblage size. Assemblage $i$ exhibits a high number of individuals within a few species, while $i i$ exhibits a small number of individuals across many species. species abundance values (i.e., $\mathrm{CS}=10), \mu_{\log }=1, \sigma_{\log }=1$; assemblage $B$ : 10 values, $\mu_{\log }=2.5, \sigma_{\mathrm{log}}=1$; assemblage $C$ : 100 values, $\mu_{\log }=1, \sigma_{\log }=0.1$; assemblage $D: 100$ values, $\mu_{\log }=4, \sigma_{\log } 0.1$ ). Following random sampling, lognormal values were placed into bins (size $=1$ ) to represent the discrete communities contained during transport. Parameters were chosen to derive assemblages exhibiting different structural characteristics (strongly uneven; assemblages $A$ and $B$; strongly even, assemblages $C$ and $D$; high PS, assemblages $B$ and $D$; high CS, assemblages $C$ and $D$ ) while adhering to a lognormal model; therefore, we illustrate the possible outcomes of PS and CS when assemblages transported by vectors follow lognormal distributions. For each iteration of each assemblage, we constructed rank-abundance distributions by plotting species abundance in decreasing order. Each of these distributions was plotted graphically in a single panel (e.g., Fig. 4A). Although rank-abundance distributions frequently utilize a log-scale for the $y$-axis, we used a linear scale to accentuate absolute differences in PS. Following 1000 iterations of each assemblage type (i.e., $n$ organisms, 1000 times, for each lognormal set), we calculated summary statistics as grand means for each of CS, minimum PS, mean PS, and maximum PS to determine the influence of assemblage structure on propagule size summary statistics across various rank-abundance gradients. Statistical analyses and simulation models were performed in $\mathrm{R}$, version 2.12.1 (R Development Core Team, 2008).

\section{RESULTS AND DISCUSSION}

Species establishment is a function of multiple interacting ecological factors and their inherent stochasticity: the colonization and propagule pressure of arriving assemblages, environmental matching between colonizing species and recipient regions, the composition of recipient communities, and many other site and species-specific attributes. Despite the number and complexity of factors required for establishment, colonization pressure and propagule pressure remain important null models for species invasions (Lockwood et al., 2005, 2009). Therefore, quantifying assemblage structure during transport is an important step towards forecasting and mitigating ecological change associated with non-native species. We address uncertainty related to propagule pressure and the structure of transported assemblages by presenting evidence of lognormal species abundance distributions for a sample of zooplankton assemblages transported by ships' ballast (Tab. 1; all $\mathrm{P}>0.05$ ). Although the extent to which lognormal models extend to other vectors or taxonomic groups outside of this study is unknown, these results indicate the existence of lognormal source communities from which transported species were removed; or, the incidence of certain mechanisms giving rise to log normality prior to, or while undergoing, transport between freshwaters. 
Because environmental disturbance may produce species abundance distributions in source communities that deviate from lognormal (Ugland and Gray, 1982), a multitude of species abundance distributions may occur in source communities given the extent of anthropogenic influence in ports and surrounding ecosystems (Ruiz et al., 2000, 2013. Generally, organisms are loaded in ballast through a random selection process that is constrained to favour certain taxonomic groups or body sizes. For example, planktonic species or benthic taxa with planktonic life stages (e.g., zebra mussel Dreissena polymorpha) may be preferentially selected, whereas large-bodied organisms (e.g., large fishes) or those predominantly occupying benthic environments are avoided due to intake screens and spatial separation, respectively. Many factors, such as diel migrations, selection for certain body densities or organism size classes, or characteristics of vectors themselves (e.g., pumping mechanisms), can result in transported species assemblages whose structure and composition differ markedly from source communities. Thus, environmental disturbance in source areas, natural variation in planktonic communities, and sampling stochasticity during uptake by vectors may produce a variety of assemblage types. Unusual forms of transported assemblages may also arise simply owing to chance alone. Due to volume of vector activity, many transported assemblages are removed from many different natural communities each year, providing increased opportunity for extremely shallow or steep rank-abundance gradients and the incidence of many species abundance distributions (e.g., geometric, logarithmic). The global community of commercial vessels is estimated to be $\sim 45,000$ (Carlton, 2001), and individual vessels may load and discharge ballast eight or more times per year (H. MacIsaac, unpublished data).
Therefore, unusual species abundance distributions during ballast water movements may occur due to several ecological, physical, and probabilistic mechanisms.

Despite the many factors that may give rise to transported assemblages deviating from their source communities, many distinct assemblages are plausible while conforming to a lognormal species abundance distribution (Fig. 3), including: steep rank-abundance gradients, indicating uneven PS among $n$ transported species (Fig. 4, assemblages $A, B$ ); shallow rank-abundance gradients, where PS is relatively consistent among $n$ transported species (Fig. 4, assemblages $C, D$ ); and, most notably, various combinations of PS and CS (low CS and PS, assemblage $A$; low CS and high PS, assemblage $B$; high CS and low PS, assemblage $C$; and, high CS and PS; assemblage $D$; Fig. 4). The potential for transported assemblages to exhibit various combinations of PS, CS, and rank-abundance gradients have three notable implications.

First, for assemblages with relatively steep rank-abundance gradients, strong variability exists among PS, indicating that simple summary measures of PS (e.g., mean, median) fail to document the variation of propagule size among species (e.g., Fig. 4, relatively large differences in minimum, mean, and maximum PS for assemblages $A$ and $B)$. In the presence of steep rank-abundance gradients, species-level characteristics are lost when relying on summary measures alone (e.g., mean PS), leading to underestimated PS for the most abundant species and strongly overestimated PS pertaining to relatively rare species. Given that many propagule pressure-species establishment relationships have relatively steep gradients (Gertzen et al., 2011), biased estimates of propagule sizes have strong ecological consequences. Therefore we encourage, at minimum, combining summary statistics (e.g.,

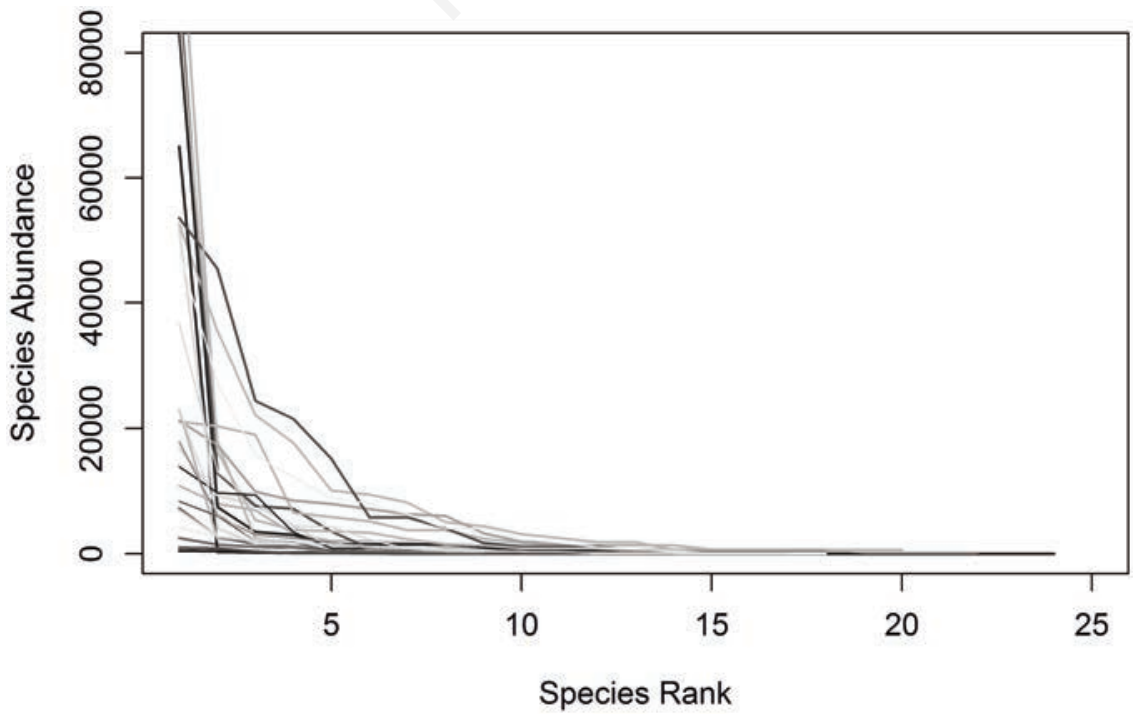

Fig. 3. Empirical species rank-abundance distributions $(n=28)$ for samples of zooplankton assemblages obtained from ballast water transported to freshwater ports in Canada (see Briski et al. 2012 for collection methods and species identities). Species abundance ( $y$-axis) represents the abundance of individuals from each species obtained from ballast water samples; species rank ( $x$-axis) represents the rank of abundance among $n$ species. 
CP and minimum, mean, and maximum PS) with the estimated parameters of species abundance distributions for a more transparent measure of the relative abundance of PS among $n$ transported species.

Second, for a given CS and assuming uniform establishment probabilities, the steepest rank-abundance gradients are likely to pose greatest establishment risk because of higher PS among $n$ transported species. In particular, steep gradients give rise to disproportionally greater PS among the most abundant species, though we acknowledge that broadly amenable conditions for establishment (e.g., environmental suitability) for dominant species is a function of the context between source and recipient regions.

Third, opposing rank-abundance gradients (e.g., steep $v s$ shallow gradients) give rise to different relative contribution of PS vs CS for assemblages of a given size (e.g., Fig. 4, assemblage $B v s$ assemblage $C$, total abundance not significantly different at $\alpha=0.05$ based on a bootstrap significance test); therefore, a given assemblage size may be associated with few species of many individuals, or many species of few individuals, altogether while conforming to an underlying lognormal species abundance distribution. As ballast volume received by individual ports and volume carried by individual ships vary tremendously (Herborg et al., 2007a; Briski et al., 2012), so too will the total abundance of transported assemblages. Therefore, in relation to a large number of transport events and the many permutations of source communities and assemblage uptake outcomes, most combinations of low or high colonization and propagule pressures are possible throughout a given yearly iteration of vector activity. The risk of establishment for any species assemblage is usually unknown given uncertainties of species identity, demographic characteristics, and the nature of the propagule pressure - species establishment relationship (Ruiz and Carlton, 2003; Carlton et al., 2011), though similar to our conceptual example (Fig. 2C), these skewed versus even assemblages may nevertheless exhibit similar potential for establishment when source-recipient environmental similarity is unknown. For example, a high PS for a single species may easily overcome demographic barriers, but with lower certainty of amenable environmental conditions in the recipient region. Conversely, speciesrich assemblages may provide many more opportunities for one of $n$ arriving species to circumvent environmental barriers, albeit with lower potential to overcome demographic constraints to establishment.

How can these results be applied to the science and management of species invasions? Propagule pressure and

Tab. 1. Assemblage number, colonization size (CS), average propagule size (mean PS), total abundance, and estimated lognormal species abundance parameters for a sample of assemblages $(n=28)$ obtained from ballast water transported among Canadian freshwater ecosystems. Also shown is the Kolmogorov-Smirnov (KS) $D$-statistic and P-value obtained during hypothesis testing.

\begin{tabular}{|c|c|c|c|c|c|c|c|}
\hline Assemblage & $\mathrm{CS}$ & Mean PS & Total abundance & $\mu_{\log }$ parameter & $\sigma_{\log }$ parameter & KS $D$-statistic & KS P-value \\
\hline 1 & 18 & 975.6 & 17560 & 5.615 & 1.978 & 0.191 & 0.527 \\
\hline 2 & 17 & 2286.3 & 38867 & 6.818 & 1.388 & 0.178 & 0.653 \\
\hline 3 & 15 & 7164.8 & 107472 & 7.325 & 1.350 & 0.237 & 0.370 \\
\hline 4 & 14 & 1182.6 & 16557 & 5.946 & 1.442 & 0.170 & 0.812 \\
\hline 5 & 18 & 409.3 & 6958 & 4.685 & 1.603 & 0.163 & 0.760 \\
\hline 6 & 16 & 51948.4 & 831175 & 9.417 & 2.393 & 0.278 & 0.168 \\
\hline 7 & 20 & 8963.1 & 179262 & 8.081 & 1.466 & 0.217 & 0.304 \\
\hline 8 & 16 & 2676.6 & 42825 & 6.481 & 1.633 & 0.196 & 0.573 \\
\hline 9 & 9 & 13596.2 & 122366 & 7.750 & 2.056 & 0.154 & 0.962 \\
\hline 10 & 19 & 5113.3 & 97172 & 7.479 & 1.877 & 0.184 & 0.538 \\
\hline 11 & 11 & 6014.4 & 66158 & 4.902 & 2.209 & 0.271 & 0.395 \\
\hline 12 & 9 & 12385.2 & 111467 & 7.504 & 1.850 & 0.216 & 0.796 \\
\hline 13 & 17 & 5548.8 & 94330 & 7.800 & 1.466 & 0.203 & 0.483 \\
\hline 14 & 18 & 10255.9 & 184606 & 7.990 & 1.610 & 0.218 & 0.359 \\
\hline 15 & 17 & 1794.0 & 30498 & 5.475 & 1.758 & 0.141 & 0.887 \\
\hline 16 & 8 & 462.9 & 3703 & 5.309 & 1.201 & 0.306 & 0.443 \\
\hline 17 & 24 & 68.1 & 1635 & 3.151 & 1.401 & 0.178 & 0.434 \\
\hline 18 & 16 & 977.0 & 15632 & 5.856 & 1.361 & 0.154 & 0.843 \\
\hline 19 & 13 & 4852.2 & 63079 & 6.621 & 1.629 & 0.166 & 0.866 \\
\hline 20 & 12 & 212.9 & 2555 & 3.642 & 2.087 & 0.131 & 0.986 \\
\hline 21 & 18 & 1003.6 & 18065 & 5.768 & 1.602 & 0.204 & 0.441 \\
\hline 22 & 22 & 6801.8 & 149640 & 7.176 & 1.453 & 0.193 & 0.388 \\
\hline 23 & 16 & 4510.9 & 72174 & 6.765 & 1.845 & 0.218 & 0.431 \\
\hline 24 & 18 & 7878.4 & 141811 & 7.690 & 1.851 & 0.149 & 0.817 \\
\hline 25 & 13 & 3029.1 & 39378 & 6.100 & 2.534 & 0.150 & 0.931 \\
\hline 26 & 14 & 1416.2 & 19827 & 5.608 & 1.869 & 0.138 & 0.953 \\
\hline 27 & 9 & 3664.6 & 32981 & 7.254 & 1.440 & 0.131 & 0.992 \\
\hline 28 & 17 & 2303.1 & 39152 & 5.576 & 2.661 & 0.181 & 0.631 \\
\hline
\end{tabular}



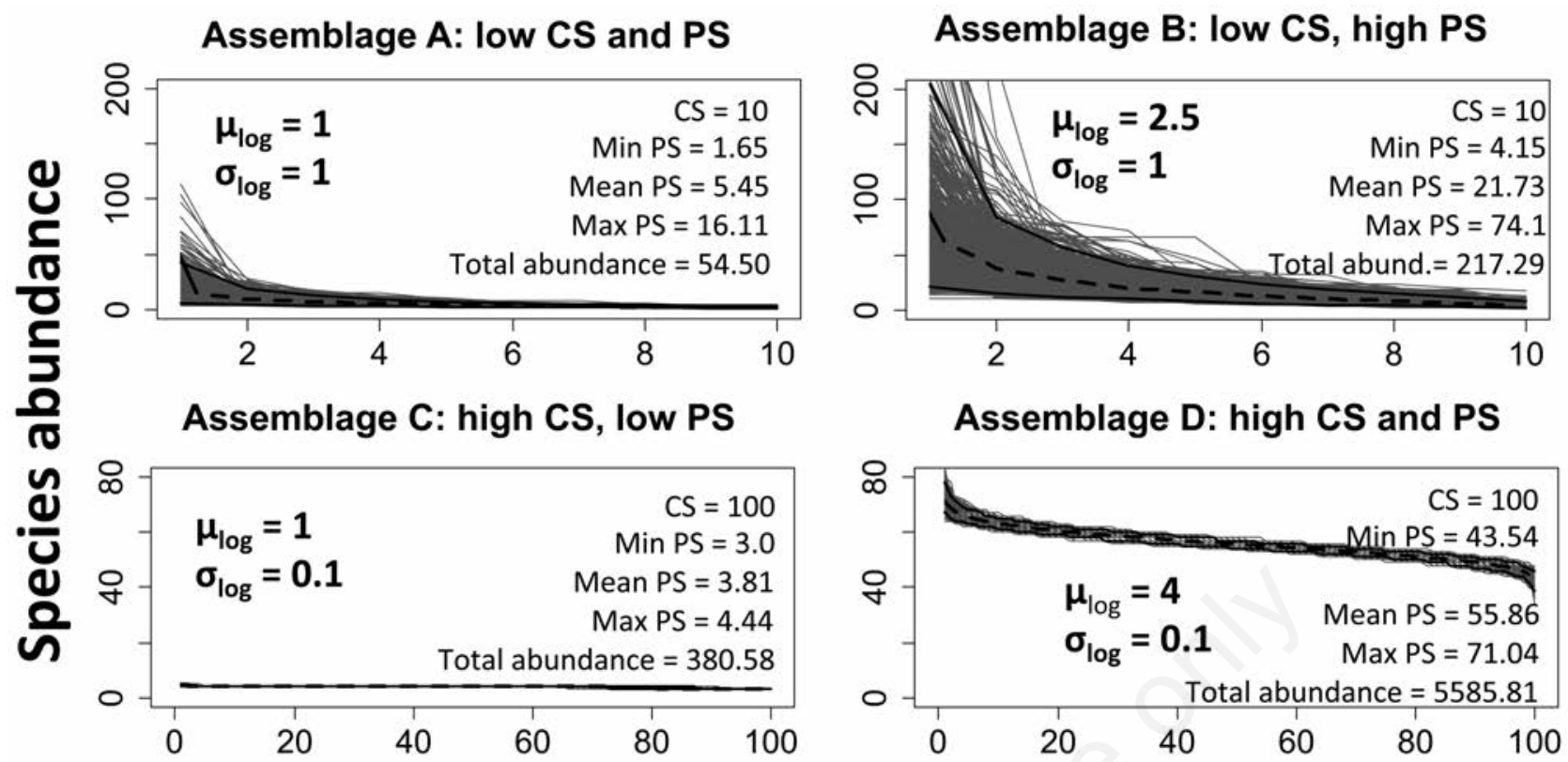

\section{Species rank}

Fig. 4. Random sampling of assemblages following lognormal species abundance distributions but exhibiting opposing rank-abundance gradients and relative contribution of colonization size (CS) and propagule size (PS) ( $n=1000$ permutations; lognormal parameters shown as inset for assemblages $A, B, C$, and $D$ ) and plotted based on rank-abundance. Summary statistics represent grand means following the permutation of 1000 assemblages for each parameter set. Grey lines represent each of the 1000 assemblage replicates; whereas, black solid lines represent the upper and lower $95 \%$ bootstrapped confidence limits; and, black dashed lines represent mean values. Note changes in $x$ and $y$ axes between assemblages $A, B$ and $C, D$.

colonization pressure are two common metrics to document assemblages transported among freshwater ecosystems. These statistics have gained widespread use in invasion ecology and their underlying principles remain as important null models for species establishment. However, researchers and managers must be aware that certain species abundance distributions have a profound effect on propagule size for a given species number. Many different outcomes of PS vs CS are possible, each with potentially different ecological implications (e.g., environmental vs demographic advantages), so assessing the species abundance distribution is a logical step to understand the contribution of PS and CS towards the potential for establishment. Our results emphasize that the investigator must be cognizant of the many possible risk profiles due to different combinations of PS and CS. In practice, given logistical sampling constraints, uncertainties with species identification, and unknown detection probabilities for many species, quantifying transported assemblages and their underlying statistical distribution is no small task, but is nonetheless an important objective towards a mechanistic understanding of species establishment.

\section{ACKNOWLEDGMENTS}

We are grateful for financial support from the CNR (Italy) for a short-term mobility grant to HJM, NSERC Discovery grants to HJM and SAB, NSERC scholarship to FC, and NSERC Visiting Fellow Stipends at Fisheries and Oceans Canada supported by Transport Canada (DARD, EB) and the Great lakes Fishery Commission (DARD).

\section{REFERENCES}

Bradie J, Chivers C, Leung B, 2013. Importing risk: quantifying the propagule pressure-establishment relationship at the pathway level. Divers. Distrib. 19:1020-1030.

Briski E, Bailey SA, Casas-Monroy O, DiBacco C, Kaczmarska I, Lawrence JE, Leichsenring J, Levings C, MacGillivary ML, McKindsey CW, Nasmith LE, Parenteau M, Piercey GE, Rivkin RB, Rochon A, Roy S, Simard N, Sun B, Way C, Weise AM, MacIsaac HJ, 2013. Taxon- and vector-specific variation in species richness and abundance during the transport stage of biological invasions. Limnol. Oceanogr. 58:1361-1372.

Briski E, Wiley CJ, Bailey SA, 2012. Role of domestic shipping in the introduction or secondary spread of nonindigenous 
species: biological invasions within the Laurentian Great lakes. J. Appl. Ecol. 49:1124-1130.

Carlton JT, 2001. Introduced species in U.S. coastal waters: environmental impacts and management priorities. Pew Oceans Commission, Arlington: 28 pp.

Carlton JT, Ruiz GM, 2005. Vector science and integrated vector management in bioinvasion ecology: conceptual frameworks, p. 36-58. In: H.A. Mooney, R.N. Mack, J.A. McNeeley, L.E. Neville, P.J. Schei and J.K. Waage (eds.), Invasive alien species: a new synthesis. Island Press, California.

Carlton JT, Ruiz GM, Byers JE, Cangelosi A, Dobbs FC, Grosholz ED, Leung B, MacIsaac HJ, Wonham MJ, 2011. Assessing the relationship between propagule pressure and invasion risk in ballast water. National Research Council (USA), Water Science and Technology Board, U.S. National Academies: $123 \mathrm{pp}$.

CBD (Convention on Biological Diversity), 1993. COP 9 Decision IX/4. In-depth review of ongoing work on alien species that threaten ecosystems, habitats or species. Available from: www.cbd.int/decision/cop/default.shtml?id=11647

Chan FT, Bailey SA, MacIsaac HJ, 2013. Relative risk assessment for ballast-mediated invasions at Canadian Arctic ports. Biol. Invas. 15:295-308.

Colautti RI, Grigorovich IA, MacIsaac HJ, 2006. Propagule pressure: a null model for biological invasions. Biol. Invas. 8:1023-1037.

Conn JS, Stockdale CA, Werdin-Pfisterer NR, Morgan JC, 2010. Characterizing pathways of invasive plant spread to Alaska: II. Propagules from imported hay and straw. Invas. Plant Sci. Management 3:276-285.

Dumont HJ, Shiganova TA, Niermann U, 2004. Aquatic invasions in the Black, Caspian, and Mediterranean Seas. Nato Science Series, Vol 35.

Edelist D, Rilov G, Golani D, Carlton JT, Spanier E, 2012. Restructuring the sea: profound shifts in the world's most invaded marine ecosystem. Divers. Distrib. 19:69-77.

Foster SD, Dunstan PK, 2010. The analysis of biodiversity using rank abundance distributions. Biometrics 66:186-95.

Gertzen EL, Leung B, Yan ND, 2011. Propagule pressure, Allee effects, and the probability of establishment of an invasive species. Ecosphere 2:1-17.

Haska CL, Yarish C, Kraemer G, Blaschik N, Whitlatch R, Zhang H, Lin S, 2012. Bait worm packaging as a potential vector of invasive species. Biol. Invas. 14:481-493.

Herborg LM, Jerde CL, Lodge DM, Ruiz G, MacIsaac HJ, 2007a. Predicting invasion risk using measures of introduction effort and environmental niche models. Ecol. Applic. 17:663-674.

Herborg LM, Mandrak NE, Cudmore BC, MacIsaac HJ, 2007 b. Comparative distribution and invasion risk of snakehead (Channidae) and Asian carp (Cyprinidae) species in North America. Can. J. Fish. Aquat. Sci. 64:1723-1735.

Hulme PE, Bacher S, Kenis M, Klotz S, Kühn I, Minchin D, Nentwig W, Olenin S, Panov V, Pergl J, Pysek P, Roques A, Sol D, Solarz W, Vilà M, 2008. Grasping at the routes of biological invasions: a framework for integrating pathways into policy. J. Appl. Ecol. 45:403-414.

Kurashov, EA, Barbashova, MA, Barkov, DV, Rusanov, AG, Lavrova, MS, 2012. Invasive amphipods as a factor of trans- formation of Lake Ladoga ecosystems. Russ. J. Biol. Inv. $3: 202-212$.

Leung B, Lodge DM, Finoff D, Shogren JF, Lewis MA, Lamberti G, 2002. An ounce of prevention or a pound of cure: bioeconomic risk analysis of invasive species. P. Roy. Soc. B 269:2407-2413.

Lockwood JL, Cassey P, Blackburn T, 2005. The role of propagule pressure in explaining species invasions. Trends Ecol. Evol. 20:223-228.

Lockwood JL, Cassey P, Blackburn T, 2009. The more you introduce the more you get: the role of colonization pressure and propagule pressure in invasion ecology. Divers. Distrib. 15:904-910.

Lockwood JL, Hoopes MF, Marchetti MP, 2007. Invasion Ecology. Blackwell Publishing, Oxford: 304 pp.

MacIsaac HJ, 2011. Lakes, p. 410-421. In: D. Simberloff and M. Rejmanek (eds.), Encyclopedia of invasive introduced species. University of California Press.

Occhipinti-Ambrogi A, Marchini A, Cantone G, Castelli A, Chimenz C, Cormaci M, Froglia C, Fumari G, Gambi MC, Giaconne G, Giangrande A, Gravili C, Mastrototaro F, Mazziotti C, Orsi-Releni L, Piraino S, 2011. Alien species along the Italian coasts: an overview. Biol. Invas. 13:215-237.

Pheloung PC, Williams PA, Halloy SR, 1999. A weed risk assessment model for use as a biosecurity tool evaluating plant introductions. J. Env. Management 57:239-251.

Preston FW, 1948. The commonness and rarity of species. Ecology 29:254-283.

R Development Core Team, 2008. R: a language and environment for statistical computing. Version 2.12.1 R Foundation for Statistical Computing, Vienna, Austria. Available from: http://www.R-project.org

Ricciardi A, 2006. Patterns of invasion of the Laurentian Great lakes in relation to changes in vector activity. Divers. Distrib. 12:425-433.

Ruiz GM, Carlton JT, 2003. Invasive species: vectors and management strategies. Island Press: $518 \mathrm{pp}$.

Ruiz GM, Fofonoff PW, Ashton G, Minton MS, Miller AW, 2013. Geographic variation in marine invasions among large estuaries: effects of ships and time. Ecol. Applic. 23:311-320.

Ruiz GM, Fofonoff PW, Carlton JT, Wonham MJ, Hines AH, 2000. Invasion of coastal marine communities in North America: Apparent patterns, processes, and biases. Annu. Rev. Ecol. System. 31:481-531.

Seebens H, Gastner MT, Blasius B, 2013. The risk of marine bioinvasion caused by global shipping. Ecol. Lett. 16:782-790.

Simberloff D, 2009. The role of propagule pressure in biological invasions. Ann. Rev. Ecol. Evol. Syst. 40:81-102.

Ugland KI, Gray JS, 1982. Lognormal distributions and the concept of community equilibrium. Oikos 39:171-178.

Von Holle B, Simberloff D, 2005. Ecological resistance to biological invasion overwhelmed by propagule pressure. Ecology 86:3212-3218.

Whittaker RH, 1965. Dominance and diversity in land plant communities. Numerical relations of species express the importance of competition in community function and evolution. Science 147:250-260.

Wonham M, Byers JE, Grosholz ED, Leung B, 2013. Modeling the relationship between invasion risk and propagule pressure to inform invasion policy. Ecol. Applic. 23:1691-1706. 